\title{
MULHER, O OUTRO: SEU CORPO E SEUS CONSTITUINTES BIOLÓGICOS, SEGUNDO SiMONE DE BEAUVOIR
}

\author{
[WOMAN, THE OTHER: HER BODY AND ITS BIOLOGICAL CONSTITUENTS ACCORDING TO SIMONE DE \\ BEAUVOIR]
}

Ester Maria Dreher Heuser * Rafaela Ortiz de Salles ** Universidade Estadual do Oeste do Paraná, Brasil

\begin{abstract}
Resumo: A partir do problema do corpo e de seus constituintes biológicos, bem como da questão do movimento de "querer ser", o artigo explora, com base na obra $O$ Segundo Sexo, de Simone de Beauvoir, como a filósofa chega à gênese da submissão da mulher, segundo a perspectiva da biologia e quais as referências biológicas que permitiram ao homem reconhecer a mulher como o Outro; afirma e mostra que o corpo biológico é o ponto de partida de toda a análise da filósofa que produziu um conjunto conceitual, rigorosamente filosófico, do corpo submetido à sociedade; por fim, defende que a análise dos dados biológicos, realizada por Beauvoir à luz da filosofia existencialista, foi primordial para o desdobramento das diversas concepções que orientam o feminismo contemporâneo.
\end{abstract}

Palavras-chave: Mulher; Corpo; Biologia
ABSTRACT: This article explores, based on the problem of the body and its biological constituents, the question of the movement of "wanting to be", based on the work $O$ Segundo Sexo, by Simone de Beauvoir. We investigated how the philosopher reaches the genesis of the submission of women, according to the perspective of biology and which are the biological references that allowed men to recognize women as the Other. This also affirms and shows that the biological body is the starting point of all the analysis of the philosopher who produced a conceptual set, rigorously philosophical, of the body submitted to society. Finally, we argue that the analysis of biological data, carried out by Beauvoir in the light of existentialist philosophy, was essential for the unfolding of the various conceptions that guide contemporary feminism.

KEYWORDS: Woman; Body; Biology

\section{INTRODUÇÃO}

o livro O Segundo Sexo, publicado em $1949^{1}$, Beauvoir investiga o que
legitimou a subordinação da mulher ao homem. Para a realização desta obra, a filósofa orienta-se por princípios da filosofia existencialista: considera que o sujeito surge em um mundo dado, com várias possibilidades de existência, porém, tais possibilidades, que Beauvoir chama de "querer ser", não são dadas à mulher. Isto porque

* Professora Associada do Curso de Filosofia (Graduação e Pós-graduação), Centro de Ciências Humanas e Sociais da na Universidade Estadual do Oeste do Paraná, UNIOESTE, Campus Toledo. E-mail: esterheu@hotmail.com. ** Universidade Estadual do Oeste do Paraná, UNIOESTE, Campus Toledo. É bolsista do Programa de Educação Tutorial (PET/Filosofia). Exbolsista do Programa Institucional de Bolsas de Iniciação à Docência (PIBID) de julho de 2016 a fevereirode 2018.E-mail: rafa-salles@hotmail.com 
um sujeito só é capaz de reconhecer-se enquanto existente no mundo se, e somente se, possuir como base de sua existência a liberdade, a qual pressupõe sua autonomia. Ao que a filósofa conclui: "A humanidade é masculina, e o homem define a mulher não em si, mas relativamente a ele; ela não é considerada um ser autônomo" (BEAUVOIR, 2016a, p. 12). Desde os primórdios da humanidade, a liberdade e as possibilidades do sujeito de se construir, tendo como referência suas próprias escolhas, foi negada à mulher. Logo, ela nunca constituiu sua condição de libertação, a qual lhe possibilitaria fazer-se sujeito de sua existência e não objeto de uma existência alheia. Em decorrência disso, a existência da mulher sempre esteve na condição de $\mathrm{Outro}^{2}$, de objeto propriamente dito.

Para problematizar esta condição, Beauvoir recorre à filosofia hegeliana, em especial à dialética do Senhor e do Escravo, presente no livro A Fenomenologia do Espírito (HEGEL, 2014). A partir dessa dialética, ao tratar do não reconhecimento das consciências, Beauvoir conclui que a mulher é o inessencial perante o essencial, pois "segundo Hegel, descobrimos na própria consciência uma hostilidade fundamental em relação a qualquer outra consciência; o sujeito só se põe em se opondo: ele pretende afirmar-se como essencial e fazer do outro o inessencial, o objeto" (BEAUVOIR, 2016a, p. 14). A mulher é em si, mas nunca para si, pois ela mesma nunca se reconheceu como mulher tomando-se como referência, nunca se autodeterminou, uma vez que o homem sempre foi, para ela, referência.

Nosso objetivo nesse artigo, fundamentalmente com base em análises da primeira parte da edição brasileira de O Segundo Sexo (2016a), é apresentar a maneira como a filósofa chega à gênese da submissão da mulher a partir da perspectiva da biologia e quais as bases biológicas que permitiram ao homem não reconhecer a mulher como indivíduo, questionando se apenas os dados biológicos valem por si só para perpetuar a condição da mulher de ser o Outro na sociedade.

\section{A GÊNESE dA SUBMisSão dA MULHER}

A moral existencialista, na qual a filósofa se baseia, aponta que o sujeito é apenas livre a partir do momento em que se concretiza como ser e, nessa condição, busca superar a existência que lhe fora determinada. Beauvoir nos apresenta dois modos de existência que cabem aos seres humanos cumprirem: a transcendência e a imanência. A transcendência refere-se ao estado em que o sujeito supera o seu modo original de existência, quando projeta, para fora de si, todos os seus desejos de libertação da espécie. Papel esse cumprido pelo homem, uma vez que o mundo lhe permitiu o reconhecimento como ser humano liberto. A imanência, por sua vez, refere-se à não superação desse estado, um estado de não-movimento existencial que acaba por degradar a própria existência. Esse é o destino da mulher, pois ela, ao descobrir-se no mundo como existente, percebe-se em um mundo masculino, ao qual the cabe cumprir o papel do Outro.

Todo sujeito coloca-se concretamente através de projetos como uma transcendência; só alcança sua liberdade pela sua constante superação em vista de outras liberdades; não há outra justificação da existência presente senão sua expansão para um futuro indefinidamente aberto. Cada vez que a transcendência cai na imanência, há a degradação da existência 'em si', da liberdade em facticidade; essa queda é uma falha moral (BEAUVOIR, 2016a, p. 26).

O homem, buscando enaltecer sua existência e transcendê-la, tornou-se a totalidade, o Um; ao subordinar a mulher ao papel do Outro na sociedade, tornou-a 
objeto de seu desejo, decretando à ela um destino cercado de imanência; "o drama da mulher é esse conflito entre reivindicação fundamental de todo sujeito que se põe sempre como o essencial e as exigências de uma situação que a constitui como inessencial" (BEAUVOIR, 2016, p. 26), pois, nunca é o Outro que, se colocando como Outro, define o Um (o essencial, a totalidade, o absoluto), o Outro foi colocado pelo Um como Outro. Porém, quando um sujeito busca afirmar-se e transcender sua existência, o Outro passa a ser objeto de seu desejo e se torna uma necessidade, pois é nele que o Um projetará tudo aquilo que ele não é.

Desde que o sujeito busque afirmar-se, o Outro, que o limita e nega, é-lhe,
entretanto necessário: ele só se atinge através dessa realidade que ele não é. Por
isso, a vida do homem nunca é plenitude e repouso, ela é carência e movimento, é
luta [...] toda consciência aspira a colocar-se como sujeito soberano. Toda
consciência tenta realizar-se reduzindo a outra à escravidão (BEAUVOIR, 2016a,
p. 199).

A filósofa ressalta a importância de nos reconhecermos e nos definirmos como mulher, pois a partir desta verdade poderemos erguer todas as afirmações seguintes. Beauvoir toma para si essa tarefa e remonta à história, com vistas a esclarecer o mito do eterno feminino, negando-o. A partir desta negação, Beauvoir nos apresenta a frase que se popularizava na sociedade francesa, "Sejam mulheres, permaneçam mulheres, tornem-se mulheres" (BEAUVOIR, 2016a, p. 9). Tal afirmação expressa a preocupação da época com a feminilidade, ela estava se perdendo. Mas, o que seria essa feminilidade? Para responder a tal pergunta, Beauvoir aponta que devemos primeiramente nos questionar: o que são as mulheres? Essa pergunta se fazia presente na sociedade do século XX: “Tota mulier in utero: é uma matriz', diz alguém. Entretanto, falando de certas mulheres ${ }^{3}$, os conhecedores declaram: 'Não são mulheres', embora tenham um útero como as outras (BEAUVOIR, 2016a, p. 9).

Se apenas a fisiologia, o sexo feminino, a presença do útero ou dos ovários não são suficientes para definir a mulher, era necessário que o "ser mulher" se afirmasse sobre outros dados. Beauvoir os investiga e constata que, desde as formas mais primitivas de vida deu-se origem aos diversos mitos e tabus que cercam a mulher, afirmando que há a existência de uma feminilidade enquanto constituinte dela. A França do século XX, quando afirmava que "a feminilidade corre perigo" (BEAUVOIR, 2016a, p. 9), estava também amparada sobre um mito que influenciou sobremaneira a existência de metade de sua população. Foi necessário, a cada mulher, por uma espécie de destino feminino, encarnar este misterioso mito da feminilidade e a ele se submeter. "Todo mito implica um Sujeito, que projeta suas esperanças e seus temores num céu transcendente. As mulheres não se colocando como Sujeito, não criaram o mito viril no qual seus projetos se refletiriam" (BEAUVOIR, 2016a, p. 202). Geração após geração, por meio de mitos que tentavam definir algo como uma "essência feminina", um "modelo" para as mulheres se perpetuou, ainda que ninguém tivesse clareza exata do que ele é. Contudo, com o desenvolvimento das ciências, mitos do tipo essencialista perderam terreno.

No tempo de santo Tomas, ela [a feminilidade] se apresentava como uma essência tão precisamente definida quanto a virtude dormitiva da papoula. Mas o conceitualismo perdeu terreno: as ciências biológicas e sociais não acreditam mais na existência de entidades imutavelmente fixadas, que definiriam determinadas características como da mulher (BEAUVOIR, 2016a, p. 10).

A filósofa considera, no entanto, que, mais do que os mitos, pesam sobre a existência das mulheres dados biológicos, psicológicos, econômicos, culturais e sociais. 
No âmbito deste artigo, os dados da biologia ganham centralidade, a fim de responder como ocorre a escravização e a alienação da mulher à própria espécie. Tal escolha se deve porque, para Beauvoir, o corpo possui uma importância significativa na construção da subjetividade das mulheres, e diz respeito ao espaço que elas ocupam na sociedade ${ }^{4}$. O corpo biológico, que é também moldado social e historicamente, ganha a atenção primeira de Beauvoir.

\section{AS BASES BIOLÓGICAS}

Como já vimos, apenas um ovário ou um útero não são suficientes para definir o ser mulher. O próprio termo "fêmea" sempre soou como algo pejorativo aos ouvidos masculinos. Os homens buscaram na biologia justificativas para o medo e a repulsa que a fêmea lhes causa. No terreno da biologia, Beauvoir se detém a um estudo do reino animal, buscando compreender, dentre as várias formas de vida deste tipo, o que a fêmea representa neste meio e por que, durante tanto tempo, os homens projetaram na mulher todas as fêmeas do reino animal.

A palavra fêmea sugere-lhe uma chusma de imagens: um enorme óvulo redondo abocanha e castra o ágil espermatozoide; monstruosa e empanturrada, a rainha das térmitas reina sobre os machos escravizados; a fêmea do louva-a-deus e a aranha, fartas de amor, matam o parceiro e o devoram; a cadela no cio erra pelas vielas, deixando atrás uma esteira de odores perversos; a macaca exibe-se impudentemente e se recusa com faceirice hipócrita; as mais soberbas feras, a leoa, a pantera, deitam-se servilmente para a imperial posse do macho. Inerte, impaciente, matreira, insensível, lúbrica, feroz, humilhada (BEAUVOIR, 2016a, p. 31).

Por milhares de anos, a divisão biológica dos sexos foi pensada a partir de mitos, tabus e opiniões, pois não havia um solo científico sobre o qual se pudesse erguer verdades. Aristóteles imaginava que o feto era fruto do encontro do esperma com o sangue menstrual. A partir desta noção aristotélica, deu-se origem ao mito da passividade feminina no processo de fecundação, a mulher apenas forneceria a matéria passiva, o útero, onde o princípio masculino inseriria toda a sua força gerando a vida, se mostrando ativo e em movimento.

Assim o óvulo, ativo em seu princípio essencial, a saber, o núcleo, é superficialmente passivo; sua massa fechada sobre si mesma, encerrada em si mesma, evoca a espessura noturna e o repouso do em si; é sob a forma da esfera que os Antigos representavam o mundo fechado, o átomo opaco; imóvel, o óvulo espera. Ao contrário, o espermatozoide aberto, miúdo, ágil, representa a impaciência e a inquietação da existência (BEAUVOIR, 2016a, p. 40).

Este mito com máscara de verdade perpetuou-se até a modernidade, os homens enalteceram a agilidade do espermatozoide, negando a atividade e a importância do óvulo. Assimilou-se, por vezes, o óvulo à imanência e o espermatozoide à transcendência. Contudo, é renunciando a essa transcendência que o espermatozoide penetra o óvulo, e no momento da fecundação há a mistura dos dois gametas, os dois abdicam de sua individualidade em prol da perpetuação da espécie. Os dois gametas inicialmente individualizados unem-se e agora encontram-se no óvulo, "juntos, eles se suprimem em sua totalidade" (BEAUVOIR, 2016a, p. 40).

[...] o óvulo é incapaz de provocar a mudança que suscitará uma nova explosão de vida; ao passo que o espermatozoide se desloca. Sem a previdência ovaria, sua 
ação seria vã; mas, sem sua iniciativa, o óvulo não cumpriria suas possibilidades ativas. Logo, concluímos que, fundamentalmente, o papel dos dois gametas é idêntico: criam juntos um ser vivo em que ambos se perdem e se superam (BEAUVOIR, 2016a, p. 41).

Sendo assim, a teoria aristotélica da passividade da fêmea é colocada em contradição, uma vez que há dois necessários para que este movimento aconteça. É a partir do óvulo que a noção de perpetuação da espécie se fortifica, pois apenas o óvulo possui maneiras de proteger, nutrir e assegurar a vida do embrião fecundado, o espermatozoide teria, então, uma existência passageira. Apesar das evidências científicas, se pode destacar uma característica de liberdade exclusiva na célula masculina e de passividade na feminina: mesmo o espermatozoide possuindo uma existência passageira, sendo ativo apenas no momento da fecundação, é ainda uma existência dotada de liberdade, sua própria estrutura o destina à mobilidade, o óvulo encontra-se encerrado no corpo feminino, fixo e imóvel, é o gameta masculino que o procura e infiltra-se nele. Mesmo o espermatozoide e o óvulo possuindo substâncias iguais, o óvulo é ativo apenas ao passo que se faz necessário ao espermatozoide; fechado em si mesmo está destinado ao repouso e à imanência. Entretanto, "os dois gametas superam-se e perpetuam-se ao mesmo tempo, mas o óvulo, em sua estrutura, antecipa as necessidades futuras. É constituído de maneira a nutrir a vida" (BEAUVOIR, 2016a, p. 41). Fundamentalmente, os dois gametas cumprem papeis idênticos, pois ambos são necessários para que a fecundação ocorra.

Ao analisar o reino animal, Beauvoir (2016a) identifica que, de baixo para cima, a vida se individualiza. Nas formas mais rudimentares da vida, os seres trabalham apenas para a reprodução da espécie. Já nos níveis mais altos, há indivíduos singulares que buscam o "querer ser", que reivindicam o reconhecimento almejado e realizado pelas consciências, o que se efetiva no desejo, "quando a vida assume formas mais complexas, esboça-se uma autonomia individual e o laço que une os sexos se afrouxa" (BEAUVOIR, 2016a, p. 45). No momento em que se concretiza a noção de criar e manter a vida, trabalho único e exclusivo de todas as fêmeas do reino animal, presenciamos a definitiva separação dos sexos.

A filósofa, primeiramente, pensa a condição da fêmea dentre as formas mais simples de vida. Nos invertebrados, como as abelhas, formigas e as aranhas é perceptível a escravização da fêmea à espécie, em alguns momentos a sua existência até pode parecer mais importante que a do macho, mas ela está devotada à espécie, escravizada por ela através da incubação, da desova e do cuidado com as larvas. Mesmo o macho possuindo uma existência mais curta, ele realiza-se enquanto indivíduo singular, efetiva sua independência. É neste campo da biologia que podemos compreender o mito da feminilidade devorante ${ }^{5}$, com base nos estudos dos matriarcados dos formigueiros e das colmeias, onde os machos, ao buscarem as fêmeas para a reprodução, morrem ou são devorados por elas, após a fecundação. O mesmo ocorre com as aranhas, as fêmeas são maiores, pois possuem uma bolsa para carregar os ovos dos filhotes até a maturidade, ela também, após o coito, devora o macho.

Nem mesmo nessas formas de vida podemos afirmar que a fêmea foi privilegiada, ou que houve uma luta dos sexos, em todos esses casos, mesmo após a derrota do macho, a fêmea permanece submetida à espécie, desovando incessantemente, não possuindo autonomia sobre sua própria existência. Já o macho, mesmo em sua existência rápida, vive sua singularidade e independência, afirma-se como ser existente, individual, "o macho paga com a vida uma futilidade em que se esboça a independência" (BEAUVOIR, 2016a, p. 47). No ato da fecundação ele exibe sua virilidade, a agilidade e a iniciativa que a fêmea não possui, é ele que a busca e a 
penetra com vistas a reproduzir a espécie. Não há e nunca houve uma luta dos sexos, a espécie escraviza a fêmea tornando-a passiva ao submetê-la aos encargos da maternidade.

Contudo, é nos mamíferos que a escravização da fêmea à espécie se fortifica. As fêmeas mamíferas possuem sua vida regulada por um ciclo sexual, já indicando que possuem um organismo adaptado para a maternidade, "todo o organismo da fêmea adapta-se à servidão da maternidade" (BEAUVOIR, 2016a, p. 49). É um organismo diferente ao do macho. No corpo feminino da espécie humana, o ciclo menstrual é responsável por consequências irreversíveis, como doenças, mudanças hormonais, corporais e mentais, das quais a mulher se torna liberta apenas após a menopausa, quando

A atividade ovariana diminui e até desaparece. Esse desaparecimento acarreta um empobrecimento vital do indivíduo. Supõe-se que as glândulas catabólicas tireoide e hipófise - esforçam-se por suprir as insuficiências do ovário; observa-se então ao lado da depressão da cessão do mênstruo, fenômenos intempestivos: baforadas de calor, hipertensão, nervosidade; recrudescência do instinto sexual. Certas mulheres acumulam, então, banha em seus tecidos; outras virilizam-se (BEAUVOIR, 2016a, p. 58).

A mulher encontra-se livre da subordinação à espécie na menopausa, seu organismo não está mais voltado para a função reprodutora. Constituem segundo a filósofa um "terceiro sexo".

Então, a mulher acha-se libertada da servidão da fêmea; não é comparável ao eunuco, porque sua vitalidade continua intacta, entretanto, não mais é presa de forças que a superam: coincide consigo mesma. Já se afirmou que as mulheres idosas constituem "um terceiro sexo", e, com efeito, não são machos e não são mais fêmeas (BEAUVOIR, 2016a, p. 59).

É nos mamíferos que o desejo de imperialismo da consciência torna-se perceptível, o macho reivindica sua individualidade, "o espermatozoide, pelo qual a vida do macho transcende-se em um outro, desgarra-se de seu corpo e se torna estranho a ele; assim o macho no momento em que supera sua individualidade, nela se encerra novamente" (BEAUVOIR, 2016a, p. 49). O macho se desprende da fêmea e apenas a reconhece como diferente, a colocando como o Outro, não mantendo uma relação de reciprocidade e reconhecimento. Raramente o macho demonstra um instinto paternal. No próprio coito a sua virilidade é confirmada, entre quase todas as espécies mamíferas é o macho que se coloca sobre a fêmea, a segura e a penetra, se permanece ao lado dela após o coito é apenas como o chefe da família.

A escravização da fêmea à maternidade se deve ao fato de que após sofrer o coito ela passa a gerar uma vida dentro de si, ela é, a um só tempo, ela mesma e outro ${ }^{6}$. Essa relação não se encerra no momento do parto, pelo contrário, torna-se ainda forte ao passo que a fêmea é a garantia da sobrevivência de sua cria, "ela aparece como possuída por forças estranhas, alienada" (BEAUVOIR, 2016a, p. 52). Esse é um dos motivos pelo qual a fêmea não é capaz de exercer uma existência individual, a própria maternidade $^{7}$ não permitiu à ela reivindicar sua individualidade, "é, portanto, permitido ao macho afirmar-se em sua autonomia: a energia específica, ele a integra em sua própria vida. Ao contrário, a individualidade da fêmea é combatida pelo interesse da espécie" (BEAUVOIR, 2016a, p. 52). Há sempre forças externas, estranhas, agindo em seu corpo que a impedem de reconhecer-se como sujeito autônomo, ela nunca se encontrou em si mesma, não se reconheceu como indivíduo singular, sempre houve a subordinação à própria espécie agindo em prol da procriação. 
Sendo a mulher a mais individualizada das fêmeas, é ela também que biologicamente mais se difere do macho, e a "que vive mais drasticamente seu destino" (BEAUVOIR, 2016a, p. 53). Desde o nascimento até a puberdade, meninos e meninas possuem o desenvolvimento igual; é durante a puberdade, com o aparecimento dos hormônios, que a espécie se afirma: o menino reconhece o corpo como sendo seu, há o desenvolvimento do orgulho fálico e de ser o que se é, porém, na menina, a manifestação da puberdade não acontece sem uma recusa do organismo, "o que ocorre nesse período perturbador é que o corpo infantil se torna corpo de mulher" (BEAUVOIR, 2016b, p. 53), há neste processo uma espécie de crise ${ }^{8}$. A mulher, desde o nascimento, sente seu corpo alienado à espécie. O ovário contém cerca de 50 mil óvulos em cada folículo, ainda na infância a menina passa por uma espécie de primeira puberdade, esses folículos incham, mas ainda não atingem a maturação. Por volta dos 14 anos, a espécie toma posse do corpo da menina, durante a puberdade "o número de folículos em via de crescimento aumenta, o ovário congestiona-se e cresce, um dos óvulos chega à maturidade e o ciclo menstrual se inicia" (BEAUVOIR, 2016a, p. 54). Quase todas as mulheres relatam que passam por perturbações durante esse período, a mulher torna-se mais emotiva e nervosa, podendo desenvolver problemas psíquicos graves, a causa de tais instabilidades se justificam biologicamente; a tensão arterial da mulher se eleva antes do corrimento sanguíneo iniciar e baixa ao término dele, a temperatura corporal sobe, o abdômen fica dolorido, algumas mulheres apresentam diarreia, perturbações nos ouvidos e na vista, dores de cabeça, mamas inchadas e doloridas, náuseas, falta de energia, cansaço, fraqueza e inchaço em algumas partes do corpo (Cf.: MURAMATSU; Et. al., 2001).

[...] o sangue veicula substâncias geralmente em reserva nos tecidos, em particular, sais de cálcio; esses sais reagem sobre o ovário, sobre a tireoide, que se hipertrofia, sobre a hipófise, que preside à metamorfose da mucosa uterina e cuja atividade se amplia; essa instabilidade das glândulas acarreta uma grande fragilidade nervosa (BEAUVOIR, 2016a, p. 56).

Da puberdade à menopausa, o corpo da mulher adapta-se às necessidades da espécie, do próprio óvulo, e nunca dela mesma, "da puberdade a menopausa, é o núcleo de uma história que nela se desenrola e que não lhe diz respeito pessoalmente" (BEAUVOIR, 2016a, p. 55). Por essa razão, a mulher nunca possui total autonomia da sua existência. $\mathrm{O}$ ciclo menstrual da mulher é o único entre todas as fêmeas que ocorre todos os meses. Todo mês, o corpo feminino se prepara para o recebimento de um embrião. É durante esse período que ela sente o corpo como não sendo seu, a espécie se apropria dele. Quando há a fecundação do óvulo, ocorre a gravidez.

Acompanha-se, não raro, durante os primeiros meses, de falta de apetite e de vômitos, que não se observam em nenhuma outra fêmea doméstica e que manifestam a revolta do organismo contra a espécie que dele toma posse; ele se empobrece em fósforo, em cálcio, em ferro, sendo este último déficit difícil de ser compensado posteriormente; a superatividade do metabolismo acentua o sistema endócrino; o sistema nervoso vegetativo fica num estado de excitabilidade intensificada; quanto ao sangue, seu peso específico diminui, torna-se anêmico (BEAUVOIR, 2016a, p. 57).

Em condições normais de saúde, ela pode não parecer nociva e não apresentar nenhum risco à mulher, contudo, traz consigo consequências irreversíveis. "O parto em si é doloroso, é perigoso" (BEAUVOIR, 2016a, p. 58), é o momento em que a mulher e a criança correm mais riscos, podendo causar danos psicológicos sérios e irreversíveis. Por isso, é apenas na menopausa que a mulher encontra sua libertação da espécie, 
reencontra o vigor que não possuía desde a primeira menstruação, contudo, "bruscamente arrancada de sua feminilidade; perde, jovem ainda, o encanto erótico e a fecundidade de que tirava, aos olhos da sociedade e a seus próprios olhos, a justificação de sua existência" (BEAUVOIR, 2016b, p. 385). O destino da mulher é cercado de imanência e passividade, "mas as passagens de um período para outro são de uma perigosa brutalidade; [...] puberdade, iniciação sexual, menopausa" (BEAUVOIR, 2016b, p. 385). No volume 2 da obra $O$ Segundo Sexo - A experiência vivida (2016b), Beauvoir relata como a crise da menopausa é sentida pelas mulheres; cada mulher atribuirá um valor simbólico e uma importância diferente à essa crise. Há um drama moral envolvido, pois muito antes da manifestação da menopausa a mulher já "sente-se obcecada pelo horror de envelhecer" (BEAUVOIR, 2016b, p. 386). Liberta da subordinação à espécie, ela continua ainda a viver drasticamente seu destino, se apavora ao perceber as limitações que a vida lhe colocou, "sendo mulher, suportou mais ou menos passivamente seu destino, parece-lhe que lhe roubaram suas possibilidades, que a enganaram" (BEAUVOIR, 2016b, p. 387). Ao passar pela crise da menopausa, a mulher repensa sua vida, sua história, seu passado e seu futuro ${ }^{9}$. Preocupa-se nesse momento em construir, viver e experienciar tudo de que foi privada em sua juventude, constituindo assim o "terceiro sexo".

Esses dados biológicos, apresentados a partir da perspectiva existencialista de Beauvoir, são importantes para compreender a história da mulher, pois "são um elemento essencial de sua situação" (BEAUVOIR, 2016a, p. 60). O corpo biológico feminino se difere drasticamente do corpo biológico masculino: esses dados nos permitem iniciar a compreensão da condição da mulher, mas não em sua situação total $^{10}$, no entanto, ele, o corpo biológico, é, sem dúvidas, seu elemento sine qua non.

\section{Considerações finais: o legado de Simone de Beauvoir}

É a partir do movimento de "querer ser", de transcendência no sentido de superação da própria espécie, que o homem se realiza. Na segunda parte do primeiro volume de $O$ Segundo Sexo (2016a), Beauvoir remonta, historicamente, o desenvolvimento das sociedades desde os primórdios da humanidade e constata que, somente a partir do descobrimento do bronze, o homem descobriu-se criador: "dominando a Natureza, não mais a teme e, em face das resistências vencidas, tem a audácia de se encarar como atividade autônoma, de se realizar na sua singularidade" (BEAUVOIR, 2016a, p. 86); ao manusear, semear e cultivar a terra com o auxílio das ferramentas, ele percebe-se como transcendência e, ao submeter a Natureza aos seus domínios, submete também a mulher dando início as sociedades patriarcais.

Como vimos, a própria fisiologia da mulher a destinou à imanência e à passividade. Contudo, para Beauvoir, o corpo corresponde a um movimento histórico e cultural. Nas próprias palavras da filósofa, o corpo "é uma situação, é nossa tomada de posse do mundo e um esboço de nossos projetos" (Beauvoir, 2016a, p. 62). Em outras palavras, sendo o nosso corpo instrumento de domínio do mundo, o corpo é constituído por experiências, um corpo situado conforme a experiência do sujeito existente que está nesse corpo e que acima de tudo é esse corpo.

Não há essencialismo na perspectiva de Simone de Beauvoir. A filósofa concebe a ideia de que há um entrelaçamento entre corpo, mente e subjetividade, o corpo e seus constituintes biológicos são um elemento importante para a formação da subjetividade, contudo, não definem o que ele é, ou o que ele quer ser. O problema não é o corpo biológico, mas é "enquanto corpos submetidos a tabus, a leis, que o sujeito toma 
consciência de si mesmo e se realiza: é em nome de certos valores que ele se valoriza" (BEAUVOIR, 2016a, p. 64). A diferença biológica, na obra de Beauvoir, é fenomenológica: é uma experiência vivida, pois "o corpo é, primeiramente, a irradiação de uma subjetividade, o instrumento que efetua a compreensão do mundo: é através dos olhos, das mãos, e não das partes sexuais que apreendem o Universo" (BEAUVOIR, 2016b, p. 11).

A experiência de possuir um corpo biológico de mulher, que vivencia todas as opressões impostas pela sociedade, juntamente com a apropriação que a própria espécie realiza, torna-se única. "É o que acontece à menina quando, fazendo o aprendizado do mundo, nele se percebe mulher. A esfera a que pertence é cercada por todos os lados" (BEAUVOIR, 2016b, p. 44). Por isso é necessário que compreendamos, minuciosamente, os dados biológicos, eles são chaves para que possamos pensar e problematizar a mulher inserida na sociedade. É a partir desses dados, em um primeiro plano, que notamos a diferenciação dos sexos e a alienação da mulher à espécie. De um lado, o homem exerce sua existência singular, ao passo que a mulher jaz subordinada à reprodução e à uma existência passiva e imanente. As variações hormonais que ocorrem na mulher contribuem para sua instabilidade, tanto física quanto psicológica. É fato que há nesses dados uma importância significativa, a partir deles podemos compreender a mulher de uma certa perspectiva ${ }^{11}$, a biológica, porém o que Beauvoir recusa é o fato de que apenas eles são suficientes para submeter a mulher à dominação do homem e a um destino cercado de imanência. $\mathrm{O}$ corpo só existe concretamente para o indivíduo na medida em que esse o apreende desde a perspectiva global de sua existência.

Mas o que recusamos, é a ideia de que [os dados biológicos] constituem um destino imutável para ela. Não bastam para definir uma hierarquia dos sexos; não explicam por que a mulher é o Outro; não a condenam a conservar para sempre essa condição subordinada (BEAUVOIR, 2016a, p. 60).

Para a filósofa, a espécie se perpetua, se realiza e transcende sua existência nas sociedades; os indivíduos não estão submetidos apenas à sua natureza, mas estabelecem, no interior das sociedades, relações e costumes que refletem em seus desejos e temores pessoais. A máxima "Ninguém nasce mulher, torna-se mulher" (BEAUVOIR, 2016b, p. 11) expressa isso, a mulher não é definida por seu corpo biológico, mas pela maneira pela qual esse corpo ganha sentidos e constrói sua subjetividade por meio da relação que estabelece com o mundo ${ }^{12}$, "é o conjunto da civilização que elabora esse produto, que qualificam de feminino" (BEAUVOIR, 2016b, p. 11).

Por isso, Beauvoir julga necessário analisarmos, ainda, para além dos dados da biologia, os dados da psicanálise e do materialismo histórico e, em seguida, nos convida para uma análise histórica do desenvolvimento das sociedades, buscando, assim, compreender como "a realidade feminina" de subordinação da mulher ao homem se constituiu. A análise desses outros dados contribuirá para que os sentidos dos dados da biologia sobre a existência da mulher tornem-se mais complexos. Sendo o seu corpo um elemento essencial para a explicação da situação que ela ocupa no mundo, por si só eles não são suficientes, isto porque as diferenças biológicas se concretizaram no interior das sociedades. Nas palavras da autora: "a passividade que caracterizará essencialmente a mulher 'feminina' é um traço que se desenvolve nela desde os primeiros anos de vida", e a filósofa completa: "Mas é um erro pretender que se trata de um dado biológico: [...] é um destino que lhe é imposto pelos seus educadores e pela sociedade" (BEAUVOIR, 2016b, p. 24). O corpo biológico, é para Beauvoir o ponto de partida de toda a sua análise, partindo dele podemos compreender a construção social do 
"feminino", um "feminino" que é constituído em meio a relações patriarcais de dominação masculina. As constatações de Beauvoir foram essenciais para o desenvolvimento dos feminismos nos anos seguintes, como por exemplo, a distinção entre sexo e gênero, com o primeiro se referindo ao fenômeno biológico e o segundo, à construção social ${ }^{13}$. O que aceitamos como "feminino" ou "feminilidade" não é uma expressão da natureza biológica, mas sim do conjunto de opressões ${ }^{14}$ e manifestações culturais que são impostas às mulheres. Simone de Beauvoir marcou a teoria feminista de modo significativo, abrindo caminhos para a construção de uma epistemologia feminista, marcada pela valorização da "experiência vivida" 15 , percepção que funda o feminismo contemporâneo.

\section{REFERENCIAS}

BEAUVOIR, Simone de. A força das coisas. 5.ed. Trad. Sérgio Milliet. Rio de Janeiro: Nova Fronteira, 2018.

BEAUVOIR, Simone de. O Segundo Sexo. Vol. I. 3.ed. Trad. Sérgio Milliet. Rio de Janeiro: Nova Fronteira, 2016a.

BEAUVOIR, Simone de. O Segundo Sexo. Vol. II. 3.ed. Trad. Sérgio Milliet. Rio de Janeiro: Nova Fronteira, 2016b.

HEGEL, Georg Wilhelm Friedrich. Fenomenologia do Espírito. 9.ed. Trad. Paulo Meneses. Rio de Janeiro: Vozes, 2014.

HISTÓRIA de um Casamento. Dir. Noah Baumbach. EUA: Heyday Films, 2019. Filme.

LEE, Rita; CARVALHO, Roberto de. Cor-de-Rosa Choque. In: LEE, Rita. Flagra. Rio de Janeiro e São Paulo: Sigla, 1982. 1 CD. Faixa 8.

NICHOLSON, Linda. "Interpretando o gênero". In: Revista Estudos Feministas, v. 8, n. 2, 2000. Disponível em: https://periodicos.ufsc.br/index.php/ref/article/view/11917. Acesso em 11 maio 2020.

MURAMATSU, H. Clarice; Et. al. "Consequências da síndrome de tensão pré-menstrual na vida da mulher". In: Revista da Escola de Enfermagem da USP, v. 35, n. 3, 2001. Disponível em: https://doi.org/10.1590/S0080-62342001000300002. Acesso em 27 mar. 2020.

RIBEIRO, Djamila. Simone de Beauvoir e Judith Butler: aproximações e distanciamentos e os critérios da ação política. Dissertação (Universidade Federal de São Paulo), 2015. Disponível em: http://repositorio.unifesp.br/bitstream/handle/11600/49071/dissertacaodjamila-tais-ribeiro-dos-santos.pdf?sequence=1\&isAllowed=y. Acesso em 13 maio 2020.

VAZ, Henrique Cláudio de Lima. "O senhor e o escravo: uma parábola da filosofia ocidental". In: Sintese, $\quad$ v. $\quad 8, \quad$ n. $21, \quad 1981$. Disponível em: https://faje.edu.br/periodicos/index.php/Sintese/article/view/2175. Acesso em 27 mar. 2020.

WOLF, Naomi. O mito da beleza: Como as imagens de beleza são usadas contra as mulheres. 1.ed. Trad. Waldéa Barcellos. Rio de Janeiro: Rosa dos Tempos, 2018.

WOOLF, Virginia. Profissões para mulheres e outros artigos feministas. Trad. Denise Bottmann. Porto Alegre: L\&PM, 2019.

YOUNG, Iris Marion. "Representação política, identidade e minorias". In: Lua Nova: Revista de Cultura e Política, n. 67, 2006. Disponível em: https://doi.org/10.1590/S010264452006000200006. Acesso em 11 maio 2020.

\section{NoTAS}

1 No Brasil, a obra foi editada e publicada em dois volumes, a saber $O$ Segundo Sexo, Vol. 1 Fatos e Mitos e O Segundo Sexo, 2016a, Vol. 2 - A Experiência Vivida, $2016 \mathrm{~b}$.

2 "A categoria do Outro é tão original quanto a própria consciência. Nas mais primitivas sociedades, nas mais antigas mitologias encontra-se sempre uma dualidade que é a do 
Mesmo e do Outro" (BEAUVOIR, 2016a, p. 13). Segundo Hegel (2014), toda consciência que se opõe a outra consciência lhe opõe também uma pretensão recíproca de reconhecimento. Ao passo que uma consciência deseja ser reconhecida, o Outro lhe é necessário. A consciência de si apenas encontra sua realização mediante outra consciência de si, buscando tornar-se em-si e para-si, conforme afirma Vaz (1981, p. 17), “[...] a consciência faz verdadeiramente a sua experiência como consciência de si porque o objeto que é mediador para o seu reconhecer-se a si mesma não é objeto indiferente do mundo, mas é ela mesma no seu ser-outro: é a outra consciência de si”. Há nesta relação uma consciência que é consciência em-si, que vive na imediatez da vida; e há uma consciência em-si, mas que está em busca de seu reconhecimento e universalização, tornar-se para-si; trava-se uma luta desigual pelo reconhecimento e liberdade, o desejo de transcender a imediatez da vida, é uma luta de vida ou de morte. Haverá sempre nessa relação uma consciência que irá transcender a imediatez da vida, que se arriscará, tornando-se Senhor; e haverá a consciência que não se arriscará, que permanecerá na dependência e na imediatez da vida, tornando-se escravo. O escravo é quem realiza a função de mediação que permite ao Senhor afirmar-se na sua independência, reconhecendo-se em-si e para-si. "Certas passagens da dialética com que Hegel define a relação do senhor com o escravo se aplicariam muito melhor à relação do homem com a mulher. O privilégio do senhor, diz, vem de que afirma o Espírito contra a Vida pelo fato de arriscar sua Vida, mas, [...] a mulher é originalmente um existente que dá a Vida e não arrisca sua vida: entre ela e o macho nunca houve combate" (BEAUVOIR, 2016a, p. 99).

3 Aqui Beauvoir refere-se aos comentários que a sociedade Francesa no início do século XX direcionava às mulheres que não performavam o ideal de feminilidade imposto. "As mulheres de hoje estão destronando o mito da feminilidade" (BEAUVOIR, 2016a, p. 10). A burguesia francesa demonstrava sua preocupação com relação ao avanço das discussões de gênero, das pautas feministas, e sobretudo a inserção das mulheres na esfera pública.

$4 \mathrm{O}$ corpo e seus constituintes biológicos são elementos essenciais para compreender o pensamento filosófico da autora, nos ajudando a problematizar a situação da mulher inserida na sociedade. Contudo, os dados biológicos não são suficientes para defini-la, "uma sociedade não é uma espécie: nela, a espécie realiza-se como existência; transcende-se para o mundo e para o futuro; seus costumes não se deduzem da biologia" (BEAUVOIR, 2016a, p. 64). O Segundo Sexo nos apresenta, de forma satisfatória, como ocorreu a construção social do feminino, mesclando dados estatísticos, experiências vividas, análises sociológicas, históricas, biológicas e psicanalíticas. Mas, "não é a fisiologia que pode criar valores. Os dados biológicos revestem os que o existente lhes confere" (BEAUVOIR, 2016, p. 64). A filósofa mostrou em sua obra como os homens utilizaram-se das diferenças biológicas para submeter a mulher a ser o Outro, mas afirmou, "a biologia não basta para fornecer uma resposta à pergunta que nos preocupa: por que a mulher é o Outro?" (BEAUVOIR, 2016a, p. 65).

5 “Observam-se os mesmos costumes na fêmea do louva-a-deus, em torno do qual se cristalizou o mito da feminilidade devorante. [...] a fêmea do louva-a-deus assassina o parceiro: tais fatos prefiguram um sonho feminino de castração" (BEAUVOIR, 2016a, p. 46). O termo "castração" possui centralidade na psicanálise freudiana. Freud supõe que a mulher se sente um homem mutilado, "a menina identifica-se, então, com o pai, mas por volta dos cinco anos descobre a diferença anatômica dos sexos e reage à ausência do pênis por um complexo de castração. Imagina ela ter sido mutilada" (BEAUVOIR, 2016a, p. 70). Beauvoir realiza uma análise crítica à teoria freudiana, afirmando que "é particularmente entre os psicanalistas que o homem é definido como ser humano e a mulher como fêmea: todas as vezes que ela se conduz como ser humano, afirma-se que ela imita o macho" (BEAUVOIR, 2016a, p. 81).

6 "Mas a gravidez é principalmente um drama que se desenrola na mulher entre si e si; ela senteo a um tempo como um enriquecimento e uma mutilação; o feto é uma parte de seu corpo e um parasita que a explora; ela o possui e é por ele possuída; ele resume todo o futuro e, carregando-o, ela sente-se ampla com o mundo; mas essa própria riqueza a aniquila: tem a impressão de não ser mais nada. [...] O que há de singular na mulher grávida é que, no 
mesmo momento em que se transcende, seu corpo é apreendido como imanente: encolhese em si mesmo, em suas náuseas e seus incômodos" (BEAUVOIR, 2016b, p. 295).

7 No filme Marriage Story (no Brasil, História de um Casamento) lançado em 2019, escrito e dirigido por Noah Baumbach, a advogada Nora Fanshaw, vivida por Laura Dern, nos 105minutos de filme, aborda o ideal de perfeição que as mães devem encarnar para serem reconhecidas socialmente como "boas" mães, o que implica também ser uma "boa" mulher. A personagem inicia: "Vamos admitir: o conceito de bom pai foi inventado há uns trinta anos. Antes disso, esperava-se que fossem caladões, ausentes, irresponsáveis e egoístas [...] mas as pessoas não aceitam esses defeitos numa mãe. Nem estruturalmente, nem espiritualmente. Porque a base dessa nossa baboseira judaico-cristã é Maria, mãe de Jesus, e ela é perfeita", e finaliza afirmando: "Deus é o pai, e Deus sequer apareceu. Então você precisa ser perfeita [...] Você sempre será julgada um nível acima”. A personagem trata do esforço que todas as mulheres e mães realizam cotidianamente para alcançar a perfeição, a qual é propriamente uma Ideia platônica, inalcançável no mundo sensível. Essa imagem "boa", denunciada pela personagem, vem ao encontro da ideia de Beauvoir quando afirma que "É fazendo-se escrava dócil que ela se torna também uma santa abençoada. Assim no coração da Idade Média, ergue-se a imagem mais acabada da mulher propícia aos homens: a figura da Virgem Maria cerca-se de glória. É a imagem invertida de Eva, a pecadora" (BEAUVOIR, 2016a, p. 236). A impossibilidade de qualquer mulher ou mãe ser bem vista, origina-se quando a nossa referência de mulher e mãe se torna a Virgem Maria. Ao dar vida à advogada Nora Fanshaw, no filme História de um Casamento, a crítica cinematográfica reconheceu a excelência da atuação da atriz Laura Dern que recebeu quatro estatuetas de Melhor Atriz Coadjuvante: Globo de Ouro 2020; Critics' Choice Awards 2020; Oscar 2020 e BAFTA Film Awards 2020.

8 “[...] a puberdade assume nos dois sexos uma significação radicalmente diferente porque não é um mesmo futuro que se anuncia a eles. [...] O menino admira em seus novos pelos promessas indefinidas: ela fica confundida diante do 'drama brutal e definido' que detém seu destino. Assim como o pênis retira do contexto social seu valor privilegiado, é o contexto social que faz da menstruação uma maldição. Um simboliza a virilidade, a outra, a feminilidade" (BEAUVOIR, 2016b, p. 63).

9 Entre 1958 e 1972 três volumes de Memórias foram publicados por Simone de Beauvoir: Memorias de uma moça bem-comportada; A força da idade; e A força das coisas. Em $A$ força das coisas (2018), Beauvoir relata sobre sua velhice. "Como pode aquilo que não tem forma nem substância - o tempo - esmagar-me com um peso grande que me faz parar de respirar? Como pode aquilo que não existe - o futuro - calcular-se tão implacavelmente? Meu $72^{\circ}$ aniversário está tão próximo. [...] Para me convencer disso, basta plantar-me diante do espelho. Aos quarenta anos um dia eu pensei: 'No fundo do espelho a velhice espreita; e é fatal, ela me pegará.' Ela me pegou. [...] Detesto a minha imagem: papos em cima e embaixo dos olhos, rosto muito cheio, e esse ar de tristeza provocado por rugas em torno da boca. Talvez as pessoas que me encontrem vejam simplesmente uma quinquagenária que não está nem bem nem mal: tem a idade que tem. Mas eu vejo minha cara velha" (BEAUVOIR, 2018, p. 635).

10 Djamila Ribeiro alerta para os riscos que a diferença biológica da mulher seja usada para explicar a diferença social e, assim, servir de argumento para legitimar a opressão à mulher, "como se dissessem: 'a mulher é isso e não há nada que se possa fazer"”. Argumento que é usado de má fé, uma vez que "pela perspectiva existencialista nenhum ser é aquilo que é, nenhuma substância é absolutamente fixa, é sempre capaz de se transformar em uma nova substância. A consciência que a mulher adquire de si mesma não seria definida unicamente pela sexualidade porque a consciência, se for fazer jus a sua definição, não pode em nenhuma hipótese estar fundada na biologia" (2015, p. 16).

11 Perspectiva que, talvez, artista nenhum soube tão bem traduzir como Rita Lee (1982), em Cor de rosa choque: "Nas duas faces de Eva / A bela e a fera / Um certo sorriso / De quem nada quer / Sexo frágil / Não foge à luta / E nem só de cama / Vive a mulher / Por isso não provoque / É cor-de-rosa choque / Não provoque / É cor-de-rosa choque / Mulher é bicho esquisito / Todo mês sangra / Um sexto sentido / Maior que a razão / Gata 
borralheira / Você é princesa / Dondoca é uma espécie em extinção".

12 Virginia Woolf (1882 - 1941) no seu texto Profissão para mulheres publicado postumamente em A morte da mariposa, 1942, problematiza: "Quer dizer, o que é uma mulher? Juro que não sei. E duvido que vocês saibam. Duvido que alguém possa saber, enquanto ela não se expressar em todas as artes e profissões abertas às capacidades humanas. E de fato esta é uma das razões pelas quais estou aqui, em respeito a vocês, que estão nos mostrando com suas experiências o que é uma mulher, que estão nos dando, com seus fracassos e sucessos, essa informação da maior importância" (WOOLF, 2019, p, 14). O texto Profissão para mulheres foi lido por Virginia Woolf para a Sociedade Nacional de Auxílio às Mulheres no dia 21 de janeiro de 1931. Em 1949 Simone de Beauvoir publica o primeiro volume da obra $O$ Segundo Sexo (2016a) que se inicia com o mesmo questionamento: "Mas, antes de mais nada: o que é uma mulher?" (BEAUVOIR, 2016a, p. 9).

13 Beauvoir é a referência primeira do debate acerca dessa distinção, pois a categoria de gênero não está fundada na Biologia, a qual apenas pode tratar da perspectiva do sexo que, por sua vez, "não é capaz de definir a mulher; sendo a mulher um indivíduo, ela também se volta ao mundo porque é escolhendo-se por meio do mundo que o indivíduo se define" (RIBEIRO, 2015, p. 17). No Brasil, sobretudo na última década, essa distinção passou a ser discutida e, seguidamente negada, entre vereadores e deputados, geralmente orientados por uma perspectiva religiosa e exclusivamente biológica, que criaram leis proibitivas relativas à tematização envolvendo diversidade de gênero. Tal discussão tornou-se litigiosa e foi tratada no Supremo Tribunal Federal (ADFP 457), em reunião virtual de 25 de abril de 2020, que decidiu ser inconstitucional vetar discussões acerca da diversidade de gênero nas escolas, uma vez que tal proibição vai contra os princípios constitucionais de igualdade de gênero, do direito à educação plural e democrática e a laicidade do Estado (mais informações sobre a decisão e os processos sobre o tema que ainda serão tratados no (https://www.cnte.org.br/index.php/menu/comunicacao/posts/noticias/73067-stfreconhece-a-inconstitucionalidade-de-proibicao-de-genero-em-escolas, acesso em 13 maio 2020).

14 O pensamento de Simone de Beauvoir ecoa fortemente nos feminismos contemporâneos que avançam na análise dos padrões estruturais de opressão, dominação, e restrição da autonomia das mulheres promovidos pelos ideais de beleza e feminilidade. Essa abordagem teórica alerta para a impossibilidade das mulheres construírem suas identidades. Naomi Wolf (1962 -), publicou em 1991 o livro O mito da beleza: Como as imagens de beleza são usadas contra as mulheres (2018), a escritora estadunidense descreve em quase quinhentas páginas como os padrões de beleza imposto às mulheres colaboram para reproduzir as desigualdades de gênero. A ideologia da beleza perpetua a condição de Outro da mulher, pois, "o mito da beleza não tem absolutamente nada a ver com as mulheres. Ele gira em torno das instituições masculinas e do poder institucional dos homens" (WOLF, 2018, p. 7); ou seja, os padrões de beleza, muitas vezes platônicos e inatingíveis, inviabilizam a construção das identidades, impedindo as condições necessárias para a autodeterminação das mulheres, o que possibilitaria a elas se reconhecerem como Sujeitos autônomos.

15 Desde os anos 1980 a teoria feminista tem estabelecido um amplo e diversificado debate, redefinindo a agenda teórica, prática e política dos feminismos. O pensamento feminista existencialista de Simone de Beauvoir, marcado pela "experiência vivida", contribuiu para a construção do pensamento filosófico político da estadunidense Iris Marion Young (1949-2006); a filósofa avançou na compreensão dos mecanismos de reprodução das desigualdades, problematizando como os corpos vivenciam suas experiências nas variadas estruturas sociais de dominação e opressão. Para tal, Young utiliza-se do conceito de perspectiva social: "uma perspectiva social não comporta um conteúdo específico determinado. Nesse sentido, a perspectiva difere do interesse e da opinião. A perspectiva social consiste num conjunto de questões, experiências e pressupostos mediante os quais mais propriamente se iniciam raciocínios do que se extraem 
conclusões. As críticas ao essencialismo apontam corretamente que pessoas, a princípio pertencentes ao mesmo grupo social, frequentemente têm interesses e opiniões diferentes e mesmo conflitantes" (YOUNG, 2006, p. 163). O conceito de perspectiva social é valioso para o pensamento feminista, partindo dele é possível tematizar a necessidade de reconhecimento dos diversos modos de vida das mulheres. A universalização abstrata e a essencialização da categoria "mulher" dão lugar agora à categoria "mulheres": plurais e heterogêneas. Linda Nicholson (1947-) defende no seu artigo Interpretando o gênero (2000), que a palavra/categoria "mulher" não tem um sentido definido e imutável, para Nicholson, "Abandonar a ideia de que pode-se definir claramente apenas um sentido para 'mulher' não significa que ela não tem sentido" (NICHOLSON, 2000 p. 35). A autora sugere "pensarmos o sentido de 'mulher' como capaz de ilustrar o mapa de semelhanças e diferenças que se cruzam. Nesse mapa, o corpo não desaparece; ele se torna uma variável historicamente específica cujo sentido e importância são reconhecidos como potencialmente diferentes em contextos históricos variáveis [...] o sentido é encontrado, não pressuposto" (NICHOLSON, 2000, p. 36). O conceito de perspectiva social, aparece revigorado nos feminismos latino-americanos do século XXI, nos possibilitando encontrar os múltiplos sentidos da categoria "mulher"; a Quarta Onda dos feminismos tem se ocupado com o decolonialismo do pensamento feminista que, por sua vez, problematiza as questões de gênero a partir da perspectiva social das mulheres latinoamericanas, valorizando a experiência única de ser uma mulher negra, indígena, quilombola, ribeirinha, entre outras. 